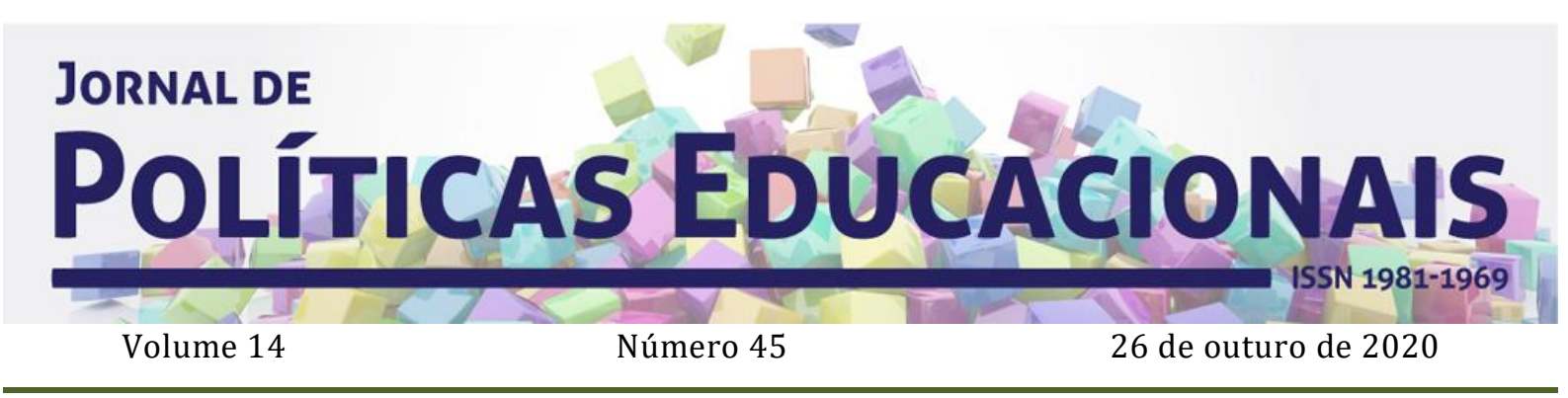

\title{
Autonomia e regulação: a descentralização da política educacional analisada como um arranjo híbrido
}

\author{
Autonomy and regulation: the decentralization of educational policy \\ analyzed as a hybrid arrangement
}

\section{Autonomía y regulación: la descentralización de la política educativa analizada como un arreglo híbrido}

\author{
Marcus Vinicius de Arevedo Braga1
}

Citação: BRAGA, M. V. de A. Autonomia e regulação: a descentralização da política educacional analisada como um arranjo híbrido. Jornal de Políticas Educacionais. V. 14, n. 45. Outubro de 2020.

http://10.5380/jpe.v14i0.73193

\begin{abstract}
Resumo
0 artigo defende que o arranjo híbrido, conceito derivado da Teoria dos Custos de Transação, pode ser uma referência teórica de discussão do processo de descentralização da política educacional a ser executada pelos municípios, por permitir uma governança que considera a autonomia e a interdependência, típicas do federalismo, apresentando a combinação de controles e incentivos, como uma maneira de se tornar essa governança menos onerosa e mais efetiva. Essa abordagem ressignifica a transparência e o controle social, como instrumentos de governança estratégica, e faz uma releitura da autonomia municipal, resgatando o seu aspecto político, de fortalecimento das capacidades estatais.
\end{abstract}

Palavras-chave: Federalismo-Municipalização-Custos de transação

\begin{abstract}
The article argues that the hybrid arrangement, a concept derived from the Theory of Transaction Costs, can be a theoretical reference for discussing the process of decentralization of educational policy to be carried out by municipalities, as it allows governance that considers autonomy and interdependence, typical of federalism, presenting the combination of controls and incentives, as a way to make this governance less costly and more effective. This approach resignifies transparency and social control, as instruments of strategic governance, and reinterprets municipal autonomy, rescuing its political aspect, of strengthening state capacities.
\end{abstract}

\footnotetext{
1 Doutor em Políticas Públicas, Estratégias e Desenvolvimento pela UFRJ (GPP/PPED/IE/UFR). Auditor Federal de Finanças e Controle da Controladoria Geral do Estado do RJ : Rio de Janeiro, RJ, BR. Orcid: http://orcid.org/0000-0002-7399-0952. E-mail: marcusbragaprofessor@gmail.com
} 
BRAGA, M. V. de A. Autonomia e regulação: a descentralização da política educacional analisada como um arranjo híbrido

Keywords: Federalism-Municipalization-Transaction costs

\section{Resumen}

El artículo argumenta que la disposición híbrida, un concepto derivado de la Teoría de los costos de transacción, puede ser una referencia teórica para discutir el proceso de descentralización de la política educativa que deben llevar a cabo los municipios, ya que permite una gobernanza que considera típica la autonomía y la interdependencia del federalismo, presentando la combinación de controles e incentivos, como una forma de hacer que esta gobernanza sea menos costosa y más efectiva. Este enfoque resignifica la transparencia y el control social, como instrumentos de gobernanza estratégica, y reinterpreta la autonomía municipal, rescatando su aspecto político, del fortalecimiento de las capacidades estatales.

Palabras clave: Federalismo-Municipalización-Costos de transacción

\section{Introdução}

O presente artigo tem como objetivo analisar em que medida a adoção dos arranjos híbridos, um paradigma da Teoria dos Custos de Transação (TCT), pode servir de referencial de discussão do fenômeno da descentralização da Política Educacional para os municípios, no contexto do federalismo brasileiro após a Constituição Federal de 1988, em especial no que se refere a tensão entre a necessidade de uma autonomia municipal, de caráter mais emancipatório, frente a uma regulação do poder central também necessária, e que fomente a coordenação.

Esse tema se reveste de importância em um momento histórico no Brasil, do final da segunda década do Século XXI, no qual esse pacto federativo se apresenta no centro de discussões públicas, repensando-se o papel da União, com a proposição da ampliação da autonomia dos entes municipais, no conceito de "Mais Brasil, menos Brasília" apresentado na campanha eleitoral presidencial de 2018, contraposto a um cenário de grande relevância da pauta da corrupção e da associação da gestão municipal a essas práticas, o que traz tensões entre se dispor de mais ou menos autonomia/regulação nesse processo.

0 problema de pesquisa se resume em responder se a adoção de um referencial teórico derivado da economia instutucional, em especial da Teoria dos Custos de Transação (TCT), permite um entendimento do fenômeno da descentralização da Política Educacional para os municípios, que contemple parâmetros para se definir a especificidade da autonomia desses entes e ao mesmo tempo, a necessidade de uma coordenação central.

Um país de dimensões continentais e com profundas desigualdades regionais, seja nos padrões educacionais aferidos pelas avaliações oficiais, seja pelas capacidades estatais dos entes para a implementação da política, tem no arranjo federalista uma 
BRAGA, M. V. de A. Autonomia e regulação: a descentralização da política educacional analisada como um arranjo híbrido

possibilidade de equalização dessas diferenças, o que torna essencial a busca de referenciais que auxiliem na melhor coordenação desses atores, os seus limites e possibilidades, em um plano federativo de mais de 5500 municípios, um cenário sui generis.

\section{Federalismo e a Política Educacional descentralizada}

1.1-0 Federalismo brasileiro e a descentralização da Política Educacional

No Federalismo, segundo Bonavides (2011), existe uma associação de estados com vistas a uma integração harmônica de seus destinos, observada a autonomia dos entes e a sua possibilidade de participação na vontade política da federação, existindo uma tendência de mitigação dessa autonomia, em função principalmente das necessidades para a redução da desigualdade regional e pela própria concentração histórica de poder nos governos centrais, no caso brasileiro.

Complementando-se essa ideia, tem-se que para Abrúcio (2010), o objetivo da federação é compatibilizar o princípio da autonomia com a interdependência entre as partes, para dar conta da heterogeneidade regional e para construir uma ideologia nacional, alicerçada por instituições, na ideia de unidade na diversidade, o que se torna complexo no caso brasileiro, quando se eleva o município a ente federativo pela Constituição Federal de 1988.

No Brasil, ao invés de uma agregação de entes, o federalismo se fez na descentralização a partir de um poder central (MARTINS, 2011), combinando-se características do patrimonialismo herdado do coronelismo (FAORO, 2001), que se reflete na gestão subnacional, oriundo de um processo colonial centralizador nas decisões, mas com autonomia na execução, uma autonomia fruto de concessões aos poderes locais, gerando uma curiosa estratificação na nossa estrutura federalista, na qual a política local se comunica intrinsecamente com o poder central.

O federalismo é um modelo adequado para países com a dimensão do Brasil, com desigualdade relevante entre os entes no que se refere aos aspectos sociais, sendo um instrumento adequado de coordenação entre os atores, por permitir a manutenção da autonomia das partes na articulação de grandes projetos nacionais, com o devido equilíbrio de pesos e contrapesos, questão essencial em um regime democrático.

A descentralização da execução é uma das características do federalismo, em especial por aproximar a implementação da população, e no caso da Política Educacional, 
BRAGA, M. V. de A. Autonomia e regulação: a descentralização da política educacional analisada como um arranjo híbrido

no contexto da chamada municipalização, tem sua estrutura definida no Art. 211 da Constituição Federal de 1988, que fala de um regime de colaboração entre os entes, com a União com uma função redistributiva e supletiva, de forma a garantir equalização de oportunidades educacionais e padrão mínimo de qualidade do ensino mediante assistência técnica e financeira aos Estados, ao Distrito Federal e aos Municípios.

Uma visão de entes que cooperam entre si, a partir de diretrizes centrais da União, na implementação dessa política. Uma visão estática, do arranjo estrutural, mas não de forças, e Cruz (2011), pontuando a discussão do pacto federativo frente a Política Educacional, aponta que:

\begin{abstract}
(...)a preocupação dos regimes federativos com o problema das desigualdades socioeconômicas regionais não é tão efetiva, bastando o mínimo de políticas compensatórias para garantir a manutenção do sistema de dominação. (...) Por isso, conclui-se que a superação das desigualdades educacionais no Brasil demanda, efetivamente, a transformação do regime vigente. Como essa mudança será fruto de um processo histórico mais complexo, a instituição de uma reforma tributária equalizadora poderia ser um marco importante para, se não solucionar, ao menos amenizar os sérios problemas detectados no modelo federativo brasileiro. (CRUZ, 2011, p.91).
\end{abstract}

Demonstrando que a questão do arranjo federativo e do papel dos atores é apenas um dos aspectos da luta por uma educação plural e de qualidade para todos, mas que não pode ser desconsiderada como frente de discussão, no aporte dos recursos necessários, da gestão adequada e participativa, e que para tal necessita repensar o papel da União e a visão da autonomia municipal, este último conceito central no presente artigo.

Entretanto, apesar dessa visão cooperativa presente na Constituição Federal, o que se tem, na prática, é que a União concentra recursos, a autoridade legislativa e a capacidade de coordenação (ARRETCHE, 2012), com restrições administrativas a autonomia dos entes municipais, pela forte regulação da implementação dessas políticas, apesar das dificuldades de monitoramento pelo poder central afetarem de forma acentuada essa regulação, e esta servir de mecanismo de enforcement na adesão de pautas e projetos top down, segundo a conveniência dos arranjos políticos.

O cenário pós eleição presidencial de 2018 apresenta uma nova proposta de pacto federativo, que se propõe a alterar o desenho da descentralização das políticas sociais, no chamado "Plano Mais Brasil", uma iniciativa do Ministério da Economia apresentada no segundo semestre de 2019, como resposta a questões de ajuste fiscal e de crescimento sustentável. 0 que se apresenta é: 
BRAGA, M. V. de A. Autonomia e regulação: a descentralização da política educacional analisada como um arranjo híbrido

(...) a defesa de maior autonomia dos governos subnacionais com a redução da responsabilidade do Governo Federal no campo das políticas públicas, mas que, num aparente paradoxo, pretende instituir isso desconsiderando os estados e municípios, a fim de enfraquecer a participação destes entes federativos na deliberação e controle das decisões tomadas em Brasília (ABRÚCIO et Alli, 2020).

O que enseja uma discussão sobre que tipo de autonomia se pleiteia no debate atual para os municípios, e que limites e possibilidades estes têm frente a função regulatória da União, para que não seja uma autonomia convertida em rompimento com os princípios do federalismo. Uma autonomia de isolamento, ou ainda, uma regulação hierárquica que exclua a articulação com os atores.

\section{2 -Autonomia e regulação na Política Educacional descentralizada}

De acordo com os estudos de Arretche (2012), a regulação da União que diminui a autonomia dos entes, possibilita a estes superar seus problemas de coordenação, trazendo benefícios a efetividade das políticas. Segundo a autora, em relação à regulação pelo poder central:

(...) a autonomia política dos governos subnacionais e a descentralização de competências não implicam necessariamente a autonomia dos governos subnacionais para implementar práticas. Essa pode ser severamente limitada pela regulação de níveis superiores de governo. Na presença de tais instrumentos de regulação, os estados federativos podem superar os problemas de coordenação que são próprios aos regimes que dispersam a autoridade (ARRETCHE, 2012, p. 158-159).

Prado (2006), nesse sentido, destaca também que a transferência condicionada foi elemento de consolidação do Estado de Bem-Estar Social em diversos países, e Lindert (2004) indica que os sistemas educacionais de maior sucesso mantêm funções de monitoramento dos entes, a despeito da descentralização da execução.

Utilizando-se de normas gerais e específicas, atua a União nessas políticas, suprindoas de transferências intergovernamentais que buscam, no entender de Prado (2006), mitigar as brechas verticais, ou seja, de equidade relativa de recursos financeiros para os entes, e também a brecha horizontal, traduzida pelas diferenças de capacidades estatais dos entes , que pode ser mitigada pelas condicionalidades e pela assessoria técnica, ainda que romper esse desnível horizontal seja extremamente mais complexo do que creditar recursos financeiros.

A autonomia dos entes, além de ser uma das características do federalismo, é uma forma de dar conta da diversidade local, no processo de implementação das políticas públicas, para ajustes e acordos, fortalecendo a inovação e a accountability por parte dos cidadãos diretamente beneficiados. 
BRAGA, M. V. de A. Autonomia e regulação: a descentralização da política educacional analisada como um arranjo híbrido

Apresenta-se assim uma tensão central na presente discussão: a autonomia como elemento de inovação, fortalecendo a eficácia na implementação da Política Educacional, associado a um ambiente de desconfiança e de descrédito do ente municipal, e os possíveis benefícios da regulação pelo poder central, no ganho em escala, na promoção da equidade e na melhor coordenação, em um dilema que pode se socorrer da discussão da TCT, como proposto no presente artigo.

\section{A Teoria dos Custos de Transação e os Arranjos híbridos}

2.1-Uma breve visão geral da Teoria dos Custos de Transação (TCT)

A ideia da TCT é parte da chamada "New Institutional Economics", e surge do trabalho seminal de Ronald Coase (1937), pesquisador que traz uma proposição inovadora em relação a visão predominante de que a direção dos recursos dependeria direta e exclusivamente dos mecanismos de preços, assumindo que existem métodos alternativos de se conduzir a produção, pois há custos significativos para se acessar mercados e para isso existe a necessidade de instituições que coordenem essas transações, visando a reduzir seus custos.

Williamson (1996), em uma de suas principais obras sobre o tema, indica que a TCT compara firmas, mercados e arranjos híbridos, em uma perspectiva de análise organizacional, como formas alternativas de gerenciamento das transações, com distintas formas de organização. O próprio autor busca definir o papel da TCT por meio de interrogações, de forma bem singela:

Algumas transações são simples e fáceis de mediar. Outras são difíceis e exigem
muito mais atenção. Podemos identificar os fatores que permitem que as
transações sejam classificadas como um tipo ou outro? Podemos identificar as
estruturas de governança alternativas dentro das quais as transações podem ser
organizadas? E podemos combinar estruturas de governança com transações de
maneira discriminatória (reduzindo custos de transação)? Essas são as questões
negligenciadas com as quais o design organizacional precisa se familiarizar.
Estes são os problemas para os quais a análise de custos de transação promete
oferecer novos insights (WILLIAMSON, 1981, p. 553) -Tradução nossa.

Ou seja, a transação surge como elemento central a ser organizado em arranjos que deem conta de sua realização, considerados os custos gerados nessa coordenação. Essa discussão de arranjo institucional é sobre o quanto é possível de salvaguardas ex-ante (prevenção), mas sem ignorar a importância das ações ex-post (correção), como asseverado também por Mahoney \& Ketokivi (2016).

E para se obter essa coordenação, essa redução de conflitos nas organizações, são necessários os arranjos institucionais adequados, que reduzam os custos de transação, 
BRAGA, M. V. de A. Autonomia e regulação: a descentralização da política educacional analisada como um arranjo híbrido

entendido por Fiani (2011) como os custos de se coordenar a atividade econômica em sociedades nas quais a divisão do trabalho já se tornou importante, pois essa divisão aumenta a relevância da interdependência e a necessidade de coordenação.

\section{2- Arranjos institucionais e a questão dos híbridos}

No que se refere ao chamado ambiente institucional no âmbito da TCT, servindose da discussão de Fiani (2013, p. 8), que adota a definição clássica de Davis e North (1971), tem-se que:

(...) um ambiente institucional (institutional environment) é constituído pelas regras políticas, sociais e legais mais básicas e gerais que estabelecem o fundamento para o funcionamento do sistema econômico. Essas regras gerais e básicas definiriam o sistema político e econômico, transcendendo as regras que os agentes privados estabeleceriam para si, nas suas transações econômicas ou nas suas relações políticas e sociais particulares, as quais, por sua vez, constituiriam arranjos institucionais. De forma geral, os autores institucionalistas se dividem entre aqueles que enfatizam o papel do ambiente institucional no desenvolvimento, e aqueles que enfocam a questão dos arranjos institucionais.

Sendo, então, o ambiente de caráter mais amplo, de mudança mais lenta, e no caso do presente artigo, o ambiente institucional é a federação, que foi objeto de uma pactuação em 1988, oriundo de uma dependência da trajetória, e se vê questionada na segunda década do Século XXI.

0 arranjo institucional é mais afeto a uma classe particular de transações, e no caso em comento, é o processo de descentralização da Política Educacional, de forma que o arranjo institucional surge para dar conta de alinhamentos ex-ante e de ajustes ex-post ${ }^{2}$, reduzindo os custos de transação. Esses arranjos se organizam de duas formas, segundo a literatura sobre o tema: a adaptação autônoma e a coordenada.

A adaptação autônoma, segundo Fiani (2011), é baseada exclusivamente em incentivos, no desenho que privilegie o chamado mecanismo de preços, típico de mercados e que sem regras específicas ou especialização, são aplicados indistintamente a qualquer transação, sem a necessidade de uma terceira parte que faça a verificação. Autônoma pelo fato de que os agentes se adaptam a mudanças no ambiente da transação de forma independente, sem a presença de nenhum tipo de coordenação. Seria a União transferir o recurso e a municipalidade se entender com a sua população no atingimento dos objetivos.

\footnotetext{
${ }^{2}$ Segundo a TCT, os contratos são incompletos. Ou seja, pela visão da racionalidade limitada, é impossível somente com salvaguardas ex-ante se dar conta do oportunismo, ou seja, a atuação de atores em benefício de interesses próprios, desalinhados, sem ser detectados, e da incerteza, sendo necessário, nesse contexto, a utilização também de salvaguardas ex-post.
} 
BRAGA, M. V. de A. Autonomia e regulação: a descentralização da política educacional analisada como um arranjo híbrido

A adaptação coordenada, um mecanismo hierárquico, também nas palavras de Fiani (2011), é adotada quando da presença de ativos específicos ${ }^{3}$, com grande interdependência entre os atores, exigindo outras formas de interação, com controles administrativos, que valorizam ações mais diretivas de uns atores sobre outros. Isto porque os investimentos dos atores são dependentes entre si, e decisões autônomas podem levar a prejuízos para os demais agentes ou, até mesmo para todos. Seria a União transferir o recurso mediante estritas e detalhadas normas de aplicação, com pesada fiscalização e punição.

Seriam os tipos de adaptação autônoma e coordenada, quando misturados, uma nova forma de arranjo institucional? Sobre esse ponto, Fiani (2013), na discussão das ideias de Williamson, indica que as hierarquias (adaptação coordenada) constituem arranjos institucionais qualitativamente distintos dos incentivos (adaptação autônoma), e que o arranjo institucional chamado de híbrido, constitui uma estrutura de governança específica, combinando incentivos e controles. Esse arranjo específico é que o presente artigo entende como categoria de análise que pode ser utilizada na Política Educacional descentralizada.

A forma híbrida, segundo Grassi (2003), sacrifica incentivos em favor da coordenação superior e, quando comparada a hierarquia, sacrifica a cooperatividade em favor da maior intensidade de incentivos, alinhando-se ao desenho da organização. E por envolver parcerias, as estruturas híbridas não operam bem em ambientes de extrema incerteza, dado que as partes têm um grau de autonomia relativa, adequando-se bem a cenários de mediana incerteza e especificidade dos ativos (WILLIAMSON, 1991), o que se vê nas transferência, com certa regularidade e dependência das partes.

Ménard (2012), estudioso francês que se deteve mais nos arranjos híbridos, indica que estes podem ser definidos como arranjos onde dois ou mais parceiros articulam decisões estratégicas e direitos de propriedade, que demandam coordenação da alocação de benefícios mútuos. $\mathrm{O}$ alinhamento entre os arranjos institucionais e as transações é o que reduz os custos de transação, quando as condições determinam sua relevância, e isso se dá pela coordenação, na busca de aumentar a cooperação e reduzir os conflitos, o que

\footnotetext{
${ }^{3}$ Os ativos específicos são uma ideia central na TCT, e segundo Williamson (1996), a especificidade de um ativo é o grau em que este não pode ser reempregado, sem sacrifício do valor produtivo, demandando complexa governança ex-post, pois os ativos específicos dificultam a possibilidade de competição, trazendo grande interdependência, gerando atores reféns, e a ameaça de substituição termina por não ser o suficiente para cobrir o risco de oportunismo.
} 
indica a relevância do modelo híbrido e a sua capacidade de combinação, em especial pela flexibilidade.

A opção por um híbrido, segundo Ménard (2006), se dá quando os investimentos entre as partes são suficientemente específicos para gerar riscos contratuais oriundos da dependência, sem ser o bastante para justificar a integração e, consequentemente, a perda de autonomia. E se justifica quando as incertezas são suficientes para requerer uma coordenação que os mercados não podem oferecer, mas sem abrir mão totalmente da autonomia. É uma forma menos onerosa de dar conta do risco de oportunismo, do ator agir por interesse próprio, concomitante ao risco de descoordenação.

Para isso, esses arranjos combinam, no seu processo de governança, controles e incentivos, em variações que vão do quase mercado à quase integração (MÉNARD, 2012), sendo importante, nesse arranjo, a pressão por competição e um bom sistema de informações entre as partes, o que reduz o risco de oportunismo, facilita o controle mútuo e consequentemente, reduz os custos de transação, bem como regras gerais e claras de caráter finalístico, que coordenem as transações respeitando a autônima das partes.

Essa combinação de controles e incentivos, como forma sugerida aqui de governança dessa rede por parte do poder central, surge em um desenho no qual os incentivos existem por conta da autonomia das partes, e os controles, devido à necessidade de coordenação, de forma que controles não entram em choque com incentivos, e vice-versa, determinando essa mescla as características dos híbridos, face à especificidade dos ativos e a incerteza.

A contratualização no híbrido é feita por acordos de longo prazo ou de curto e automaticamente negociáveis, com a necessidade do estabelecimento de padrões de qualidade, uniformidade, e a força desses contratos, chamados relacionais, reside na maior dependência deles da reputação das partes, e de um menor detalhamento (maior autonomia na implementação), substituindo o enforcement legal e possibilitando as adaptações necessárias, em especial em ambientes de repetidas interações (MÈNARD, 2011), como é a descentralização de políticas para os municípios. Ou pelo menos deveria ser.

3. A descentralização da política educacional analisada como um arranjo híbrido

3.1-Descentralização e arranjos híbridos 
A descentralização se materializa por transferências intergovernamentais, no apoio técnico e financeiro da União, organizadas essas transações em programas de suplementação da Política Educacional nos municípios, consistindo, via de regra, do repasse de recursos, com condicionalidades e normativos, para que os municípios executem a política por meio de sua mão de obra, própria ou terceirizada, e também de seus recursos próprios, existindo a presença de outros formatos, como compra centralizada pela União de insumos, por exemplo. Mas em todos os desenhos existe, de alguma forma, um regramento da União sobre a utilização dos recursos, dado que são programas de caráter nacional.

Nesse cenário, o FNDE-Fundo Nacional para o Desenvolvimento da Educação, autarquia do Ministério da Educação (MEC) que gerencia esse processo de descentralização, gera um fluxo constante de repasses aos municípios, por meio de transferências financeiras, suportando parte significativa da Política Educacional, sendo o agente principal nesse processo de parceria previsto na Constituição Federal de 1988.

Na adoção de uma visão de arranjo híbrido para analisar a política educacional descentralizada, tem-se que essas transferências e o seu arcabouço normativo se aproximam do conceito de contrato relacional, pois não se preocuparia em debater exaustivamente todos os procedimentos a serem adotados, apenas metas e objetivos, e as condições gerais do contrato, especificando critérios e circunstâncias imprevistas (FIANI, 2016), tentando capturar a adaptação ex-post, contando com regras de entrada rígidas. Um modelo que contemplaria a visão de autonomia e interdependência, presente nos arranjos híbridos e também no federalismo.

Williamson (1996a), ao tratar dos contratos relacionais, os indica para transações padronizadas e recorrentes, com uma pressão para se sustentar a relação, utilizando-se da chamada governança trilateral, que segundo Fiani (2002) é a especificação, ex-ante, de uma terceira parte, tanto na avaliação da execução, como para a solução de eventuais litígios, que poderia ser uma proposição para o papel, nesse modelo, da CGUControladoria-Geral da União, do próprio FNDE, ou ainda, de uma instância interfederativa, que ainda não existe.

No que se refere a essa caracterização como um contrato relacional, tem-se que a análise dos programas mais conhecidos, em relação as suas resoluções mais estruturantes, indica um grau de detalhamento ainda elevado, fragilidades nas regras de 
BRAGA, M. V. de A. Autonomia e regulação: a descentralização da política educacional analisada como um arranjo híbrido

entrada, e pouco espaço para ajustes ex-post, fatores que distanciam a prática de um modelo relacional, conforme detalhado no quadro a seguir:

Quadro 1- Análise das resoluções dos programas educacionais

\begin{tabular}{|c|c|c|c|}
\hline Resolução FNDE & $\begin{array}{l}\text { Detalhamento } \\
\text { procedimental }\end{array}$ & $\begin{array}{l}\begin{array}{l}\text { Possibilidade } \\
\text { ajustes ex-post }\end{array} \\
\text { de }\end{array}$ & Regras de entrada \\
\hline $\begin{array}{l}\text { Resolução CD/FNDE no } \\
\text { 26/2013 (PNAE) }\end{array}$ & $\begin{array}{l}\text { A descrição das regras } \\
\text { para os cardápios é bem } \\
\text { detalhada, em que pese } \\
\text { já se exija dos } \\
\text { municípios a presença } \\
\text { de um nutricionista. } \\
\text { Permite às estratégias } \\
\text { de educação alimentar } \\
\text { listadas na norma } \\
\text { especificamente. Não se } \\
\text { refere à questões de } \\
\text { performance ou } \\
\text { indicadores. }\end{array}$ & 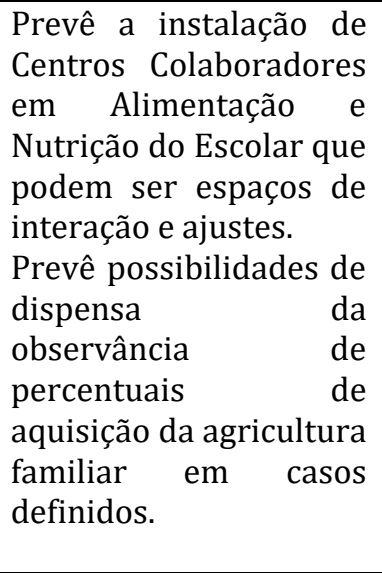 & $\begin{array}{l}\text { Tem exigências rígidas } \\
\text { em tese, como a } \\
\text { delegação formal pelos } \\
\text { estados aos municípios, } \\
\text { existência de estrutura } \\
\text { necessária, inclusive de } \\
\text { profissionais de } \\
\text { nutrição, e de conselho } \\
\text { de alimentação escolar, } \\
\text { em que pese a norma } \\
\text { não indique os } \\
\text { mecanismos de aferição } \\
\text { das condições antes da } \\
\text { adesão. }\end{array}$ \\
\hline $\begin{array}{l}\text { Resolução/CD/FNDE no } \\
42 / 2012 \text { (PNLD) }\end{array}$ & 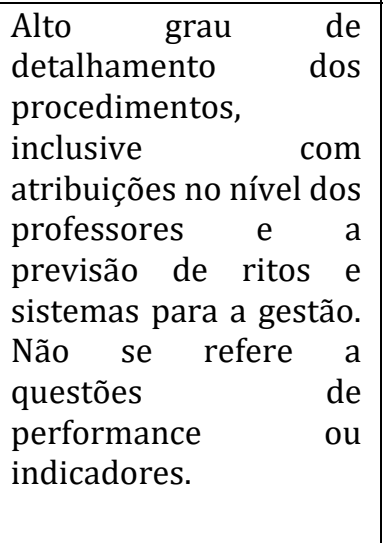 & $\begin{array}{l}\text { Permite ajustes } \\
\text { quantitativos apenas, e } \\
\text { a participação dos } \\
\text { professores ex-ante nas } \\
\text { consultas temáticas, } \\
\text { bem como adaptações } \\
\text { às peculiaridades } \\
\text { regionais a partir do } \\
\text { MEC. Prevê a solicitação } \\
\text { de justificativas diante } \\
\text { de ajustes de } \\
\text { quantidades. }\end{array}$ & $\begin{array}{l}\text { As regras de entrada } \\
\text { são simples, na linha da } \\
\text { adesão pelo município, } \\
\text { sem a indicação, por } \\
\text { exemplo, se o município } \\
\text { utiliza sistema } \\
\text { apostilado, ou se ele tem } \\
\text { estrutura para guarda } \\
\text { ou redistribuição dos } \\
\text { livros. Para exclusão do } \\
\text { sistema necessita de } \\
\text { provocação formal do } \\
\text { município. }\end{array}$ \\
\hline $\begin{array}{l}\text { Resolução /CD/FNDE } \\
\text { no 12/2011 (PNATE) }\end{array}$ & $\begin{array}{l}\text { Bom nível } \text { de } \\
\text { detalhamento, em } \\
\text { especial na questão da } \\
\text { gestão financeira e da } \\
\text { prestação de contas, } \\
\text { detalhando alguns } \\
\text { aspectos operacionais } \\
\text { na linha de adesão a } \\
\text { normas, e não em } \\
\text { termos de performance } \\
\text { ou indicadores. }\end{array}$ & $\begin{array}{l}\text { Dá certa autonomia a } \\
\text { gestão, estabelecendo } \\
\text { um ról de aplicações } \\
\text { dentro do escopo de } \\
\text { transporte escolar, mas } \\
\text { sem indicações } \\
\text { específicas de ajustes, } \\
\text { com certo grau de } \\
\text { padronização, inclusive } \\
\text { nos procedimentos de } \\
\text { gestão. }\end{array}$ & $\begin{array}{l}\text { Não tem regras } \\
\text { específicas de entrada } \\
\text { definidas nas normas, } \\
\text { bastando ter alunos na } \\
\text { zona rural, não } \\
\text { definindo requisitos } \\
\text { que indiquem a } \\
\text { capacidade de gerir os } \\
\text { recursos para as } \\
\text { finalidades pactuadas. }\end{array}$ \\
\hline
\end{tabular}

Fonte: Sítio do FNDE/Construção do autor

Como se vê, o detalhamento é na linha de aderência a normas e ritos procedimentais, com uma discussão ausente de performance ou indicadores, desconsiderando as peculiaridades locais. No que tange a ajustes ex-post, são bem tímidas as possibilidades, com situações de grande padronização oscilando com autonomia restrita a finalidades definidas. Talvez uma decorrência da visão de que normas detalhadas inibem iniquidades. Em relação a regras de entrada, constata-se uma grande 
BRAGA, M. V. de A. Autonomia e regulação: a descentralização da política educacional analisada como um arranjo híbrido

fragilidade, pois quando não ausentes, são indicadas sem elementos de verificação e restrição.

O detalhamento procedimental, com poucas possibilidades de ajuste ex-post, denota um desenho de busca pela padronização, pouca autonomia municipal, falta de confiança nas relações entre os entes e subalternidade em relação a União, em um contexto no qual os problemas da gestão municipal reforçam essa visão de desconfiança, e de arranjos que não favoreçam a emancipação do município, o fortalecimento de suas capacidades estatais, inclusive em relação a accountability, restando uma visão muito tutelada, que onera todo o processo de transferências intergovernamentais, e o afasta de um arranjo híbrido, e que tem um potencial questionável de evitar os temidos desvios.

0 arranjo híbrido, como paradigma, pode contribuir com uma governança que combine controles e incentivos, reduzindo os custos de transação, de forma a ressignificar a transparência e o controle social, como mecanismo de fortalecimento da accountability local e de competição entre os atores municipais, com a disputa por desempenho no ganho do jogo político, como no caso do Índice de Desenvolvimento da Educação BásicaIDEB $^{4}$, e fora da Política Educacional, a Escala Brasil Transparente ${ }^{5}$.

A visão hierárquica, centrada em normativos detalhados, aumenta os custos de monitoramento, ressarcimento, análise de prestação de contas, o que termina resultando em ações pontuais, necessárias, mas perde-se as possibilidades de ganhos em incentivos, com visões globais, agregadas, contribuindo com uma forma menos onerosa de governança dessas transações, valorizando o controle político e os ganhos advindos de ações bottom up.

A autonomia é essencial para o sucesso da implementação da Política Educacional, e chega a ser ingênuo acreditar que em um universo de mais de 5500 munícipios, em diversidade de estrutura, apenas um conjunto de regras rígidas e procedimentais é o suficiente para garantir o desempenho na ponta, sem a utilização de incentivos, que alimentam os controles políticos.

\section{2-Autonomia e implementação da Política Educacional nos municípios}

\footnotetext{
${ }^{4}$ O IDEB é o Índice de Desenvolvimento da Educação Básica, criado em 2007 pelo Instituto Nacional de Estudos e Pesquisas Educacionais Anísio Teixeira (Inep), e foi formulado para medir a qualidade do aprendizado nacional e estabelecer metas para a melhoria do ensino.

${ }^{5}$ Trata-se de uma estratégia de incentivo da transparência municipal promovida pela CGU, por meio da avaliação e divulgação de um ranking nacional, o que reduz a incerteza no ambiente municipal, e fomenta a aderência pela linha da busca do lucro político, sintonizado a visão de incentivo dos arranjos híbridos da TCT.
} 
BRAGA, M. V. de A. Autonomia e regulação: a descentralização da política educacional analisada como um arranjo híbrido

A matriz cartorial presente no país, do autoritarismo que quer tudo definir, traz a reboque uma visão que atribui a discricionariedade a causa de todos os problemas. Mas ela é essencial em políticas mais bottom up, como a Educação, e quanto a efetividade das regras, Hill (1997) indica que existem dificuldades do uso pelo cidadão da lei para se proteger dos abusos da burocracia e ainda, que não é simples estabelecer a relação das regras com a conduta dos agentes no cotidiano, e que a busca de resoluções judiciais onera sobremaneira os processos, em uma visão bem harmonizada as discussões da TCT.

Faz-se necessário uma autonomia que seja fortalecedora das capacidades estatais, em uma via emancipatória, e não tuteladora. Não são apenas equipamentos públicos. Capacidades estatais, definidas por Gomides e Pires (2014), tem uma faceta técnicoadministrativa, pela ação da burocracia weberiana na construção de Políticas Públicas de qualidade; e um aspecto político, de expansão dos canais de interlocução e negociação com atores sociais.

A questão das capacidades é crucial para a confiança no sistema federativo. E Acemoglu e Robinson (2012), ao tratarem dos auxílios humanísticos das grandes potências para mitigar a miséria dos países da África Subsaariana, da América Central e do Sul da Ásia, em uma lógica similar à brecha vertical do federalismo e às transferências intergovernamentais, mostram que esses países pobres têm problemas por conta de suas instituições extrativistas, pela ausência de direitos de propriedades, lei e ordem, sistema jurídico adequado e a sufocante presença das elites nacionais, similar às deficiências de capacidades estatais de municípios de do Brasil.

Para esses autores, essa ajuda externa será ineficaz, pois será usurpada e dificilmente chegará às mãos dos reais destinatários, e mesmo os programas de ajuda humanitária que passaram a exigir condicionalidades dos países beneficiários não tiveram sucesso, pois os que se mostram incapazes de atingir a performance requerida são os mais necessitados, e acabam, ao final, recebendo ajuda mesmo assim. Uma lógica similar à dependência da União com os municípios na implementação.

Nesse ponto, os autores trazem luz à essa questão pela via institucionalista, em uma ideia que pode ser importada para a discussão de capacidades aqui tratada. Eles defendem a importância da autonomia, para que o país beneficiário tenha condições de desenvolver as suas capacidades políticas. Nas palavras dos autores:

Como vimos, a resposta não está na condicionalidade, já que esta requer que os atuais governantes façam concessões; pelo contrário, uma perspectiva mais positiva talvez consistisse na estruturação da ajuda externa de modo que seu 
BRAGA, M. V. de A. Autonomia e regulação: a descentralização da política educacional analisada como um arranjo híbrido

emprego e administração insiram no processo decisório grupos e lideranças de resto excluídos do poder, empoderando assim um amplo segmento da população (ACEMOGLU; ROBINSON, 2012, p. 351).

De forma que as capacidades estatais, em especial as políticas, relacionadas ao chamado controle social, que não vive sem seu irmão siamês, a transparência, são centrais na promoção da qualidade da Política Educacional descentralizada, e pode-se inferir que as transferências verticais, por si só, não são suficientes para resolver essa questão, o que faz com que o transferidor principal, a União, amplie a sua preocupação com aspectos emancipatórios do ente municipal, e a visão dos arranjos híbridos, de combinação de controles e incentivos nessa governança, auxilia esse entendimento.

O apoio técnico da União não pode ser somente capacitação, de caráter procedimental. Precisa atingir o fortalecimento local dos mecanismos de accountability (BRAGA, 2015), reduzindo, inclusive, os custos de transação do concedente de recursos federais para monitorar e supervisionar a atuação no nível municipal, em um modelo de governança menos diretivo, mantendo regulação e autonomia em uma outra forma de relação. Uma autonomia que tenha incentivos para se alinhar com a política nacional, associada a uma regulação sobre aspectos mais amplos da política.

As discussões trazidas no presente tópico indicam que essas desigualdades regionais se auto alimentam, sendo a causa da dificuldade de emancipação, mas também a consequência. A história mostra que em períodos de crise financeira, a descentralização que repassa mais custos das políticas sociais aos municípios é adotada no Brasil, desonerando o poder central, e consequentemente aumentando as desigualdades em vários sentidos, o que pode sacrificar gerações.

A Educação no município não é só um conjunto de prédios e equipamentos públicos, mas tem também um aspecto imaterial, de adesão à causa, de mobilização, que envolve também a capacitação dos atores, e um arranjo que possibilite a articulação de esforços para que o município, pela sua atuação, "transforme metas e objetivos educacionais em ações, dando concretude às direções traçadas pela Política (BORDIGNON; GRACINDO, 2006, p.147)", por meio de Planos Municipais de Educação, do Projeto Político Pedagógico e de uma valorização docente, dos funcionários e da relação da escola com a família.

Não adianta desmerecer na relação à estrutura de gestão municipal, real, fruto de um processo descentralizador e executório de caráter histórico, e sim estimular a accountability horizontal, nas organizações de controle locais, e a vertical, no fomento ao 
BRAGA, M. V. de A. Autonomia e regulação: a descentralização da política educacional analisada como um arranjo híbrido

controle político, a transparência e a participação social, para que os municípios promovam a inovação e a qualidade dos serviços e tenham incentivos para tal.

\section{Conclusão:}

O presente artigo importa da ciência econômica o conceito de arranjos híbridos, oriundo da Teoria dos Custos de Transação, de matriz institucionalista, como um desenho proposto para a análise do processo de descentralização da Política Educacional no ambiente institucional do federalismo brasileiro, após 1988, em especial na tensão entre regulação central e autonomia municipal.

A falta de confiança nos municípios, como ator no processo de implementação dessa política, bem como uma trajetória um tanto autoritária desse federalismo, imputam um papel executivo as municipalidades, com regras rígidas e detalhadas, com uma visão de assistência técnica focada na capacitação, em uma visão tecnicista que privilegia pouco a articulação dos atores, incentivos e ações de emancipação do município, que oscila entre desacreditado e ineficiente, mas que, em última instância, é o baluarte desse processo de implementação, por estar mais próximo do cidadão.

Os arranjos híbridos dão suporte a uma visão que mescle a rigidez das regras com mecanismos de incentivos, recordando que esse processo é eivado de interdependência, e que a autonomia é um valor essencial no processo de implementação e ajuste da política em cada realidade municipal, evitando custos de transação de monitoramento dessa rede de mais de 5500 municípios, o que na prática é impossível, trazendo esse processo para uma visão estratégica e que realmente traga avanços para a Política Educacional.

Incentivo não é uma desresponsabilização, mas sim a adoção de outras estratégias de governança, menos hierárquicas, que se utilizem dos controles políticos, tutelando menos diretamente as municipalidades, fazendo destas mais participes, mas entendendo que só a transparência e o controle social não são efetivos, sendo necessários também ações mais diretivas, mas que existam em harmonia e consonância, como nos arranjos híbridos, alinhando controles e incentivos, para o melhor gerenciamento das transações, com o menor ônus.

\section{Referências:}

ABRUCIO, Fernando Luiz. A dinâmica federativa da educação brasileira: diagnóstico e propostas de aperfeiçoamento. In: OLIVEIRA, Romualdo Portela de; SANTANA, Wagner 
BRAGA, M. V. de A. Autonomia e regulação: a descentralização da política educacional analisada como um arranjo híbrido

(Org.). Educação e federalismo no Brasil: combater as desigualdades, garantir a diversidade. Brasília: Unesco, 2010.

ABRUCIO, Fernando Luiz; GRIN, Eduardo José; COUTO, Cláudio; SEGATTO, Catarina; FRANZESE, Cibele. Mais Brasil, Menos Brasília: o sentido do federalismo bolsonarista e seu impacto no combate à Covid 19. Blog Gestão, Política \& Sociedade (Estadão), 2020. Disponível em: <https://politica.estadao.com.br/blogs/gestao-politica-esociedade/mais-brasil-menos-brasilia-o-sentido-do-federalismo-bolsonarista-e-seuimpacto-no-combate-a-covid-19/> . Acesso em: 26 abr. 2020.

ACEMOGLU, Daron; ROBINSON, James A. Por que as nações fracassam: as origens do poder, da prosperidade e da pobreza. Rio de Janeiro: Elsevier, 2012.

ARRETCHE, Marta Teresa da Silva. Democracia, federalismo e centralização no Brasil. 1aㅡ Ed. Rio de Janeiro: Editora FGV; Editora Fiocruz, 2012.

BONAVIDES, Paulo. Ciência Política. 18ạ. Ed. São Paulo: Malheiros Editores, 2011.

BORDIGNON, Genuíno; GRACINDO, Regina Vinhaes. Gestão da educação: o município e a escola. In: FERREIRA, Naura Syria Carapeto; AGUIAR, Marcia Angela da S. (Org.). Gestão da Educação: impasses, perspectivas e compromissos. 5ạ. Ed. São Paulo: Cortez, 2006. p. 147-176.

BRAGA, Marcus Vinicius de Azevedo. Conselhos do Fundeb: participação e fiscalização no controle social da educação. -1aㅡ. Ed. Curitiba: Appris, 2015.

COASE, Ronald H. The nature of the firm. Economica, v. 4, p. 386-405. London, 1937.

CRUZ, Rosana Evangelista da. Federalismo e financiamento da Educação: a política do FNDE em debate. In: GOUVEIA, Andréa Barbosa; PINTO, José Marcelino Rezende; CORBUCCI, Paulo Roberto. Federalismo e políticas educacionais na efetivação do direito à educação no Brasil. Brasília: Ipea, 2011. p. 79-94.

DAVIS, L. E.; NORTH, D. C. Institutional change and American economic growth. Cambridge: Cambridge University Press, 1971.

FAORO, Raymundo. Os donos do poder: formação do patronato político brasileiro. 3a . Ed. São Paulo: Editora Globo, 2001.

FIANI, Ronaldo. 0 problema dos custos de transação em parcerias público-privadas em infraestrutura. Texto para discussão nํ2261/ Instituto de Pesquisa Econômica Aplicada- Brasília: Rio de Janeiro: Ipea, 2016. Disponível em: <https://www.ipea.gov.br/>. Acesso em: 26 abr. 2020. 
BRAGA, M. V. de A. Autonomia e regulação: a descentralização da política educacional analisada como um arranjo híbrido

. Teoria dos custos de transação. In KUPFER, D.; HASENCLEVER, L. Economia

Industrial: fundamentos teóricos e práticas no Brasil. Rio de Janeiro: Campus, 2002.

Arranjos institucionais e desenvolvimento: o papel da coordenação em

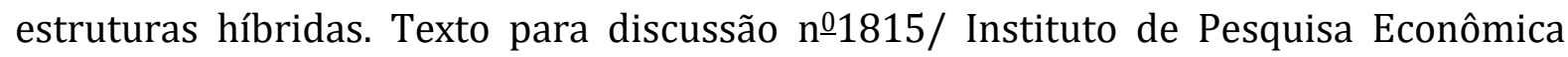
Aplicada. - Brasília: Rio de Janeiro: Ipea, 2013. Disponível em: <https://www.ipea.gov.br/>. Acesso em: 26 abr. 2020.

. Cooperação e conflito: instituições e desenvolvimento econômico. Rio de Janeiro: Elsevier, 2011.

GOMIDE, Alexandre de Avila; PIRES, Roberto Rocha C. Analise comparativa: arranjos de implementação e resultados de Políticas Públicas. In: GOMIDE, Alexandre de Avila; PIRES, Roberto Rocha C. Capacidades estatais e democracia: arranjos institucionais de Políticas Públicas. Brasília: Ipea, 2014. p. 351-379. Disponível em: <https://www.ipea.gov.br/>. Acesso em: 26 abr. 2020.

GRASSI, Robson Antônio. Williamson e "formas híbridas": uma proposta de redefinição do debate. Revista Economia e Sociedade, Vol. 12.1, pp : 43-64, Campinas, 2003.

HILL, M. The Policy Process in the Modern State. 3a Edição. Londres, UK: Prentice Hall, 1997.

KETOKIVI, Mikko; MAHONEY, Joseph T. Transaction Cost Economics As a Constructive Stakeholder Theory. Academy Of Management Learning \& Education, [s.l.], v. 15, n. 1, p. 123-138, mar. 2016. Academy of Management. http://dx.doi.org/10.5465/amle.2015.0133.

LINDERT, Peter H. Growing Public: social spending and economics growth since the eighteenth century. Nova York: Cambridge University Press, 2004.

MARTINS, Paulo de Sena. Fundeb, federalismo e regime de colaboração. CampinasSP/Brasília-DF: Autores Associados/Faculdade de Educação da UnB. 2011 MÉNARD, Claude, Hybrid Organization of Production and Distribution. Economic Analysis Review, Vol. 21, No. 2. Santiago, 2006. Disponível em: <https://ssrn.com/abstract=1239162>. Acesso em: 26 abr. 2020. Hybrid Modes of Organization. Alliances, Joint Ventures, Networks, and Other 'Strange' Animals. In: R. Gibbons; ROBERTS J, The Handbook of Organizational Economics. Princeton: Princeton University Press. Chapter 26: 1066-1108, 2012.

PRADO, Sérgio. Equalização e federalismo fiscal: uma análise comparativa. 1aㅡ Ed. Rio de Janeiro: Konrad-Adenauer -Stiftung, 2006. 
BRAGA, M. V. de A. Autonomia e regulação: a descentralização da política educacional analisada como um arranjo híbrido

WILLIAMSON, Oliver E. The mechanisms of governance. Oxford: Oxford University Press, 1996.

- Comparative economic organization: the analysis of discrete structural alternatives. Administrative Science Quartely, v. 36, p. 269-296, 1991.

. The governance of contractual relations. In: PUTTERMAN, Louis; KROSZNER,

Randall S. The economic nature of the firm: A reader. Cambridge University Press, 1996a.

. The Modern Corporation: Origins, Evolution, Attributes. Journal of Economic

Literature, Vol. 19, December, pp. 1537-1568, 1981. 

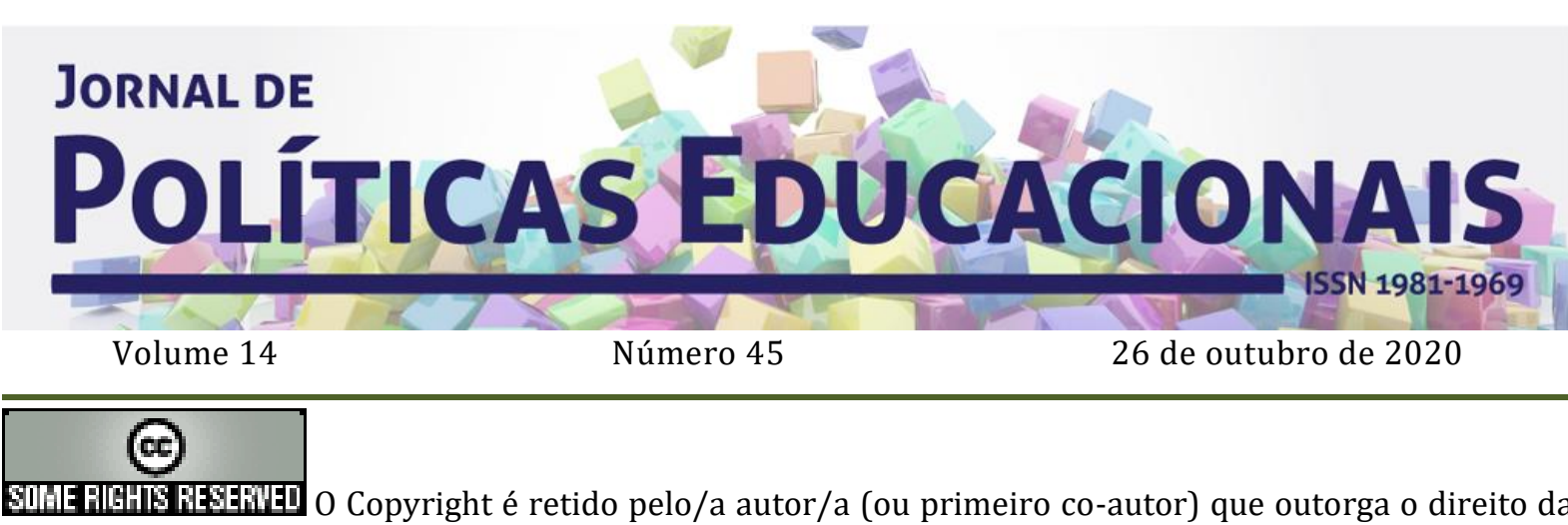

Jright é retido pelo/a autor/a (ou ph primeira publicação ao Jornal de Políticas Educacionais. Mais informação da licença de Creative Commons encontram-se em http://creativecommons.org/licenses/by-nc-nd/2.5. Qualquer outro uso deve ser aprovado em conjunto pelo/s autor/es e pelo periódico.

JORNAL DE POLÍTICAS EDUCACIONAIS é uma publicação do Núcleo de Políticas Educacionais do Setor de Educação da Universidade Federal do Paraná - NuPE/UFPR, em consórcio com a Linha de Pesquisa em Políticas Educacionais do Programa de Pós-Graduação em Educação - PPGE/UFPR, que aceita colaboração, reservando-se o direito de publicar ou não o material espontaneamente enviado à redação. As colaborações devem ser enviadas ao NuPE/UFPR, conforme orientações contidas nas páginas do periódico na internet: http://revistas.ufpr.br/ipe.

Indexação:

BBE - Biblioteca Brasileira de Educação (MEC/INEP)

Clase (Base de Datos Bibliográfica de Revistas de Ciencias Sociales y Humanidades)

Diadorim - Diretório de Política de Acesso Aberto das Revistas Científicas Brasileiras (IBICT)

Google Scholar

Index Copernicus

Portal de Periódicos (CAPES)

SER - Sistema Eletrônico de Revistas da Universidade Federal do Paraná (SER/UFPR)

Sumários de Revistas Brasileiras (FUNPEC-RP)

DRJI - Directory of Research Journals Indexing

(Periódico integralmente disponível apenas em via eletrônica)

Jornal de Políticas Educacionais / Núcleo de Políticas Educacionais da Universidade Federal do Paraná NuPE/UFPR - v.1, n. 1 (1ํo semestre de 2007) - Curitiba: NuPE/UFPR.

Volume 14, número 45 - Outubro de 2020

ISSN 1981-1969

1. Educação - Periódicos. 2. Política Educacional - Periódicos. I. NuPE/UFPR

Comitê Editorial:

Elisângela Scaff (UFPR)

Daniela de Oliveira Pires (UFPR)

Conselho Editorial:

Andréa Barbosa Gouveia (UFPR - Brasil), Cesar Tello (Universidad Nacional Tres Febrero, Argentina), Fernanda Saforcada (Universidad de Buenos Aires - UBA - Argentina), Gladys Beatriz Barreyro (USP Brasil), Gustavo Enrique Fischman, (Arizona State University - USA), Jefferson Mainardes (UEPG - Brasil), João Ferreira de Oliveira (UFG - Brasil), Juca Gil (UFRGS - Brasil), Luiz Souza Júnior (UFPB - Brasil), Ney 
BRAGA, M. V. de A. Autonomia e regulação: a descentralização da política educacional analisada como um arranjo híbrido

Cristina Monteiro de Oliveira (UFPA - Brasil), Nicolás Bentancur, (Universidad de la República de Uruguay), Robert Verhine (UFBA - Brasil), Rosana Cruz (UFPI - Brasil), Rubens Barbosa Camargo (USP - Brasil), Sebastián Donoso Díaz (Universidad de Talca - Chile), TheresaAdrião (UNICAMP - Brasil), Vera Peroni (UFRGS - Brasil).

Créditos e Agradecimentos:

Revisão de Língua Portuguesa, Abstract e Resumen: PROGRAMA DE APOIO ÀS PUBLICAÇÕES CIENTÍFICAS PERIÓDICAS DA UFPR

Arte e diagramação: TIAGO TAVARES (iagotav@gmail.com)

Jornal de Políticas Educacionais

Universidade Federal do Paraná

Setor de Educação

Núcleo de Políticas Educacionais - NuPE/UFPR

Avenida Sete de Setembro, 2645

$2^{\circ}$ andar, Sala 213

80.230-010 - Curitiba - PR - Brasil

Tel.: 41-3535-6264

jpe@ufpr.br

http://revistas.ufpr.br/jpe 